\title{
Associations between the acclimation of phloem-cell wall ingrowths in minor veins and maximal photosynthesis rate
}

\author{
William W. Adams III ${ }^{1}$, Christopher M. Cohu ${ }^{1+}$, Véronique Amiard ${ }^{2}$ and Barbara Demmig-Adams ${ }^{1}$ \\ 'Department of Ecology and Evolutionary Biology, University of Colorado, Boulder, CO, USA \\ ${ }^{2}$ Genomics and Bioinformatics Unit, Agriaquaculture Nutritional Genomic Center, Temuco, Chile
}

Edited by:

David McCurdy, The University of Newcastle, Australia

Reviewed by:

Nabil I. Elsheery, Tanta University, Egypt

Hazem M. Kalaji, Warsaw University of Life Sciences, Poland

\section{${ }^{*}$ Correspondence:}

William W. Adams III, Department of Ecology and Evolutionary Biology, University of Colorado, Boulder, CO 80309-0334, USA

e-mail:william.adams@colorado.edu

${ }^{\dagger}$ Present address:

Christopher M. Cohu, Dow

AgroSciences, Portland, OR, USA.
The companion cells (CCs) and/or phloem parenchyma cells (PCs) in foliar minor veins of some species exhibit invaginations that are amplified when plants develop in high light $(\mathrm{HL})$ compared to low light (LL). Leaves of plants that develop under $\mathrm{HL}$ also exhibit greater maximal rates of photosynthesis compared to those that develop under $L L$, suggesting that the increased membrane area of CCs and PCs of HL-acclimated leaves may provide for greater levels of transport proteins facilitating enhanced sugar export. Furthermore, the degree of wall invagination in PCs (Arabidopsis thaliana) or CCs (pea) of fully expanded LLacclimated leaves increased to the same level as that present in $\mathrm{HL}$-acclimated leaves 7 days following transfer to $\mathrm{HL}$, and maximal photosynthesis rates of transferred leaves of both species likewise increased to the same level as in HL-acclimated leaves. In contrast, transfer of Senecio vulgaris from LL to HL resulted in increased wall invagination in CCs, but not PCs, and such leaves furthermore exhibited only partial upregulation of photosynthetic capacity following $\mathrm{LL}$ to $\mathrm{HL}$ transfer. Moreover, a significant linear relationship existed between the level of cell wall ingrowths and maximal photosynthesis rates across all three species and growth light regimes. A positive linear relationship between these two parameters was also present for two ecotypes (Sweden, Italy) of the winter annual $A$. thaliana in response to growth at different temperatures, with significantly greater levels of PC wall ingrowths and higher rates of photosynthesis in leaves that developed at cooler versus warmer temperatures. Treatment of LL-acclimated plants with the stress hormone methyl jasmonate also resulted in increased levels of wall ingrowths in PCs of $A$. thaliana and $S$. vulgaris but not in CCs of pea and S. vulgaris. The possible role of PC wall ingrowths in sugar export versus as physical barriers to the movement of pathogens warrants further attention.

Keywords: biotic defense, companion cells, light acclimation, leaf vasculature, phloem, photosynthesis, temperature acclimation, transfer cells

\section{INTRODUCTION}

Transfer cells, specialized for facilitating movement of molecules or ions into or out of cells as a result of enhanced cell-membrane area into which transport proteins are embedded, can be found at key junctures within and between plant tissues (Offler et al., 2003). The increased cell membrane area is achieved through invagination of the cell wall, leading to a labyrinth of wall and plasma membrane. In seeds of cotton, greater cell-wall ingrowths have been associated with a higher yield of fiber and seed biomass (Pugh et al., 2010), presumably due to greater fluxes of reduced carbon and nutrients from the mother plant to the developing seed. On the other hand, seed development was inhibited in a pea line with a mutation that blocked development of transfer cells between mother plant and seed (Borisjuk et al., 2002). There is thus clear evidence for a role of transfer cells in increasing the flux of nutrients into sinks resulting in enhanced sink development.

Transfer cells also occur in source tissues, e.g., in the phloem of minor leaf veins (Gunning etal., 1968; Offler et al., 2003). Such cells show enhanced levels of invagination in response to various environmental conditions, including growth at higher levels of light (Henry and Steer, 1980; Wimmers and Turgeon, 1991) and, for the winter annual Arabidopsis thaliana, growth at lower temperatures (Edwards et al., 2010). Leaves of most plants grown in high compared to low light (Amiard etal., 2005), as well as those of winter annuals grown at low compared to warm temperature (Adams etal., 2013; Cohu etal., 2013b, 2014), exhibit higher rates of light- and $\mathrm{CO}_{2}$-saturated photosynthesis, and may therefore have a higher capacity for foliar sugar export. The extent to which transfer-cell enhancements in minor veins may enable increased levels of source activity has received little attention, although greater levels of sucrose export were associated with higher levels of wall ingrowth in pea (Wimmers and Turgeon, 1991). In addition, it was noted that pea leaves grown under high versus low light had both higher maximal rates of photosynthesis and higher levels of companion cell wall ingrowths (Amiard etal., 2005). Furthermore, several species exhibited greater levels of wall ingrowth in either phloem parenchyma or companion cells (or both cell types) 
in leaves grown under high versus low light (Amiard et al., 2007).

In the present study, a comprehensive examination of associations between the extent of foliar minor-vein transfer-cell wall ingrowth and photosynthetic capacity was undertaken for leaves of three species grown under three different growth light regimes and for the leaves of two ecotypes of $A$. thaliana grown under three different temperature regimes. In addition, the impact of the stress hormone methyl jasmonate on foliar phloem-cell wall ingrowths is also reviewed, calling for a resolution (by future research) of the question of an involvement of phloem-parenchyma cellwall ingrowth in either sugar export (as suggested by correlations between ingrowth level and maximal photosynthesis rate) and/or potential physical barriers to the passage of pathogens (as suggested by the responsiveness to methyl jasmonate).

\section{MATERIALS AND METHODS}

\section{PLANTS, GROWTH CONDITIONS, AND EXPERIMENTAL TREATMENTS}

Three species with transfer cells in their foliar minor veins (Pate and Gunning, 1969; Henry and Steer, 1980; Haritatos et al., 2000), A. thaliana (L.) Heynhold (ecotype Columbia, i.e., Col-0), Pisum sativum L. cv. Alaska (pea), and Senecio vulgaris L., were grown as described in Amiard et al. (2007) under either $100 \mu \mathrm{mol}$ photons $\mathrm{m}^{-2} \mathrm{~s}^{-1}$ (low light $=\mathrm{LL}$ ) or $1000 \mu \mathrm{mol}$ photons $\mathrm{m}^{-2} \mathrm{~s}^{-1}$ (high light $=\mathrm{HL}$ ) at $25^{\circ} \mathrm{C}$ during the day and $20^{\circ} \mathrm{C}$ during the night. A third group of plants were grown under LL-conditions and then abruptly transferred to HL-conditions for a period of seven days. A fourth and fifth group of plants were grown under LL-conditions and sprayed daily with a solution of either $10 \mu \mathrm{M}$ methyl jasmonate (MeJA) in water and $0.05 \%$ Tween or only water and $0.05 \%$ Tween (control group for the MeJA-treated group) for 7 days. To evaluate the impact of growth temperature on transfer-cell wall ingrowths and photosynthesis, two ecotypes of $A$. thaliana (from Sweden and Italy; see Ågren and Schemske, 2012) were grown as described in Cohu et al. (2013a) under $400 \mu \mathrm{mol}$ photons $\mathrm{m}^{-2} \mathrm{~s}^{-1}$ with day/night leaf temperatures of approximately $14 / 12.5^{\circ} \mathrm{C}, 18 / 15^{\circ} \mathrm{C}$, or $36 / 25^{\circ} \mathrm{C}$. Only mature leaves that had expanded fully under the respective light and temperature growth conditions were characterized, with the exception that leaves transferred from LL to HL, or sprayed with a solution, had expanded fully prior to the 1-week treatment in each case.

\section{MINOR-VEIN TRANSFER CELL CHARACTERIZATION}

Leaf tissue was fixed, sectioned, and stained, and electron micrographs of minor veins imaged, as described in Amiard et al. (2005). The percentage increase in cross-sectional cell membrane perimeter, relative to such cells possessing no cell wall ingrowths, was determined according to Wimmers and Turgeon (1991) as described in Amiard etal. (2005) using EEB Viewer software or
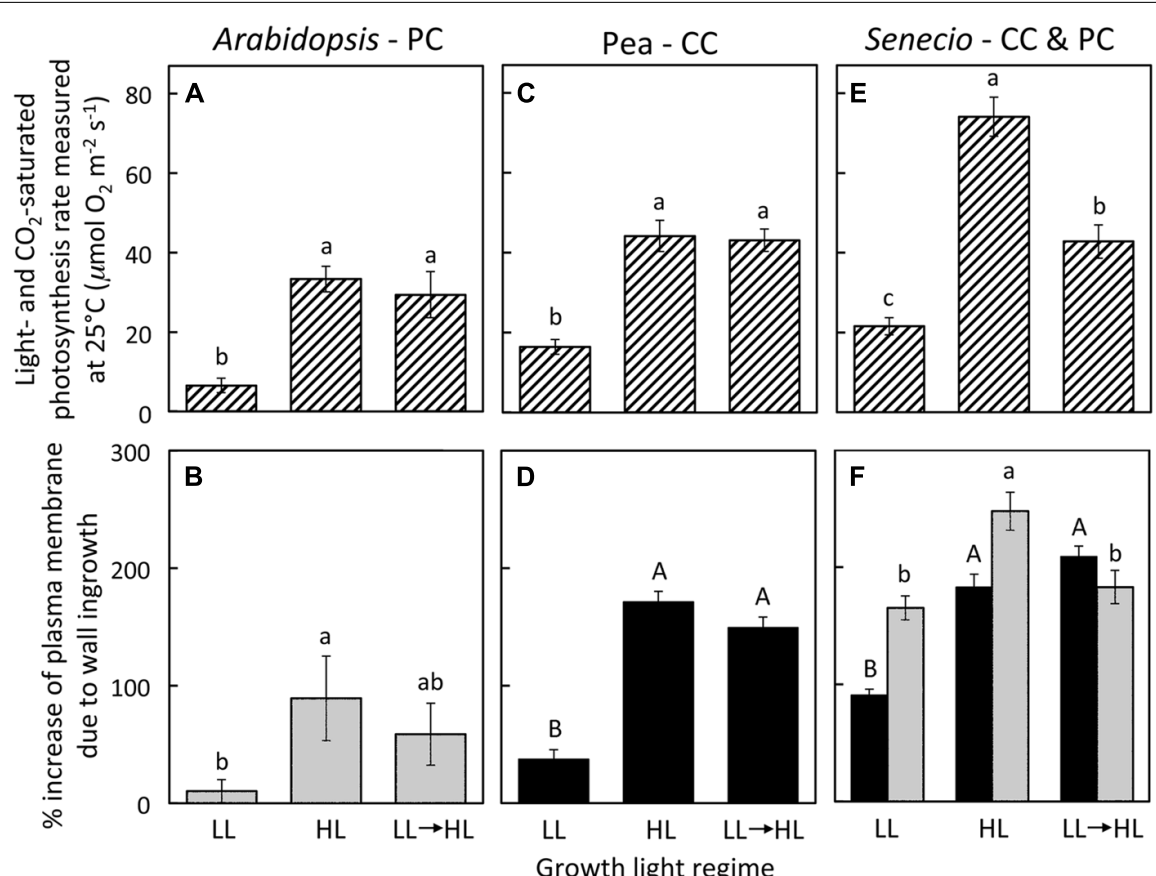

FIGURE 1 | (A,C,E) Foliar light- and $\mathrm{CO}_{2}$-saturated rate of photosynthetic oxygen evolution ascertained at $25^{\circ} \mathrm{C}$ and (B,D,F) percent increase in plasma membrane length due to cell wall ingrowths estimated from cross-sections of phloem transfer cells (parenchyma $=\mathrm{PC}$, companion $=$ $\mathrm{CC})$ relative to the hypothetical membrane area in the absence of wall ingrowths in foliar minor veins of $A$. thaliana $(\mathbf{A}, \mathbf{B})$, pea $(\mathbf{C}, \mathbf{D})$, and S. vulgaris $(\mathbf{E}, \mathbf{F})$ that developed in low light $(\mathrm{LL})$, high light $(\mathrm{HL})$, or $\mathrm{LL}$ and then transferred to $\mathrm{HL}$ for seven days. Light-gray columns indicate
PCs and black-filled columns indicate CCs. Significant differences between means $(P<0.05)$ within each species are denoted by different lower-case letters, with the exception that upper-case letters are used to designate significant differences among the level of cell wall ingrowths for CCs, i.e., means sharing a common letter are not statistically different from each other. Photosynthetic capacities for pea from Amiard etal. (2005) and for A. thaliana and S. vulgaris grown in HL from Amiard etal. (2007). 
Image-J (Rasband W. S., ImageJ, U.S. National Institute of Health, Bethesda, MD, USA, http://imagej.nih.gove/ij/, 1997-2012).

\section{PHOTOSYNTHETIC CAPACITY (MAXIMAL RATE OF PHOTOSYNTHESIS)}

The rate of light- and $\mathrm{CO}_{2}$-saturated photosynthetic oxygen evolution at $25^{\circ} \mathrm{C}$ in a water-saturated atmosphere was determined from leaf disks (Delieu and Walker, 1981) as described in Amiard et al. (2005). Saturating levels of $\mathrm{CO}_{2}$ (5\%) were provided to overcome all resistances (stomatal, cuticular, and mesophyllrelated) to $\mathrm{CO}_{2}$ diffusion to the chloroplasts. Saturating light of 1,475 or $2,425 \mu \mathrm{mol}$ photons $\mathrm{m}^{-2} \mathrm{~s}^{-1}$ was used for leaves grown under 100 versus 400 and $1000 \mu \mathrm{mol}$ photons $\mathrm{m}^{-2} \mathrm{~s}^{-1}$, respectively.

\section{STATISTICAL ANALYSES}

For the Columbia ecotype of A. thaliana (Col-0), pea, and S. vulgaris, mean values of light- and $\mathrm{CO}_{2}$-saturated photosynthetic oxygen evolution ( \pm standard deviation) were determined from three leaves from three different plants, and mean values for percent increase in plasma membrane length ( \pm standard error) were determined from 26 to 87 cells from three to six leaves each. In the case of the Swedish and Italian ecotypes of $A$. thaliana, mean values of light- and $\mathrm{CO}_{2}$-saturated photosynthetic oxygen evolution ( \pm standard deviation) were determined from three to four leaves from three to four different plants, and mean values for percent increase in plasma membrane length ( \pm standard error) were determined from 27 to 48 cells from three to four leaves each. Comparison of means (ANOVA or $t$-test) and correlation coefficients and significance level of linear relationships (ANOVA) were determined using JMP software (SAS Institute, Cary, NC, USA).

\section{RESULTS}

Growth of $A$. thaliana, pea, and $S$. vulgaris under HL resulted in leaves with significantly higher photosynthetic capacities (maximal rates of photosynthesis; Figures 1A,C,D) and foliar minor veins with phloem transfer cells possessing a significantly higher level of cell-wall ingrowths (Figures 1B,D,F) compared to leaves from plants grown under LL. Photosynthetic capacity of fully expanded leaves of $A$. thaliana and pea was not statistically different from (i.e., was equivalent to) the high rates of HL-acclimated leaves one week following transfer of LL-acclimated plants to HL (Figures 1A,C), and the extent of transfer-cell wall invagination of minor vein phloem was also not statistically different between HL-acclimated leaves and those transferred from LL to HL (Figures 1B,D). On the other hand, fully expanded leaves of S. vulgaris plants transferred from LL to HL exhibited only partial upregulation of photosynthesis that was not only significantly higher than that of LL-acclimated leaves, but also significantly lower than that of HL-acclimated leaves (Figure 1E). The extent of minor-vein companion cell (CC) wall ingrowths of LL-to-HL transferred $S$. vulgaris leaves was significantly greater than that of LL-acclimated leaves and equivalent to that of HL-acclimated leaves (Figure 1F). On the other hand, minor-vein parenchyma cell (PC) wall ingrowths of LL-to-HL transferred S. vulgaris leaves were the same as that of LL-acclimated leaves and therefore significantly lower than that of HL-acclimated leaves (Figure 1F).
Plotting of the data from Figure 1 revealed a positive linear relationship between the level of minor-vein phloem transfer-cell wall ingrowth and photosynthetic capacity among all three species and all three growth-light conditions (Figure 2).

Development of leaves at low temperature (Figures 3B,D) resulted in enhanced levels of minor-vein phloem-PC wall ingrowths and photosynthetic capacities in both Italian (Figures 3A,B) and Swedish (Figures 3C,D) ecotypes of $A$. thaliana compared to development at warmer temperature (Figures 3A,C), such that both parameters were significantly higher in leaves of both ecotypes that developed at a leaf temperature of $14^{\circ} \mathrm{C}$ compared to leaves that developed at $36^{\circ} \mathrm{C}$ (Figure 4). Moreover, there were linear relationships between the level of such foliar minor-vein PC wall ingrowths and photosynthetic capacity of the leaves for each ecotype across three growth temperatures, with both metrics increasing significantly between growth at warm versus low temperature (Figure 5).

Treatment of LL-acclimated leaves with methyl jasmonate for one week resulted in a significantly greater level of cell wall ingrowths in the foliar minor vein phloem PCs of both $A$. thaliana (Figure 6A) and $S$. vulgaris (Figure 6C), but had no impact on the level of cell wall ingrowths in minor-vein phloem CCs of either pea (Figure 6B) or S. vulgaris (Figure 6C).

\section{DISCUSSION}

The regulatory factors modulating deposition of cellulose and lignin to form wall ingrowths are a subject of active research (e.g., Edwards et al., 2010; Arun Chinnappa et al., 2013). It has recently

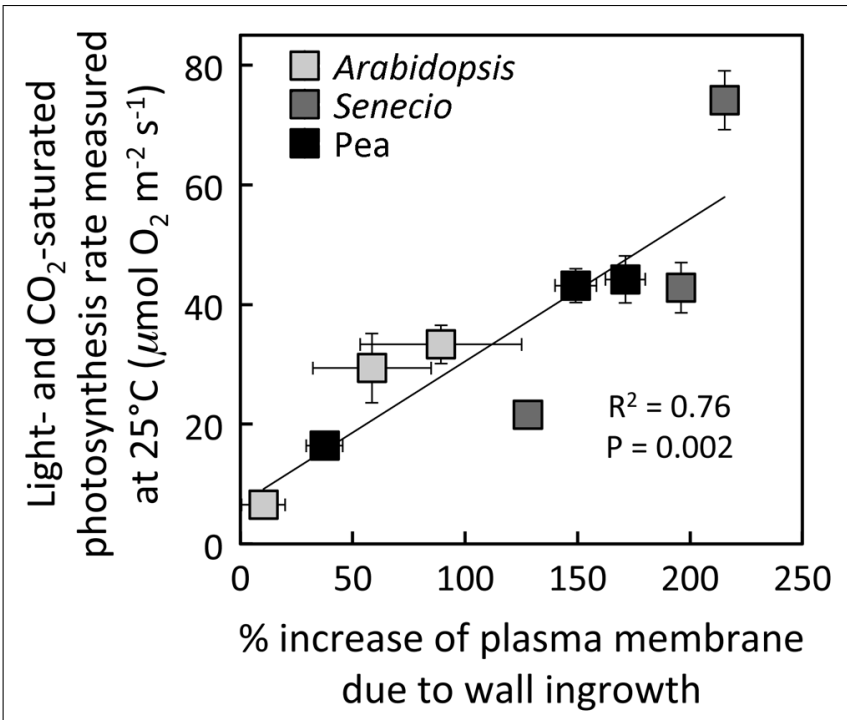

FIGURE 2 | Relationship between the percent increase of transfer-cell plasma membrane length in foliar minor veins and photosynthetic capacity from leaves of $A$. thaliana (light gray), pea (black), and $S$. vulgaris (dark gray) developed under $\mathrm{LL}$ or $\mathrm{HL}$, or seven days after transfer of leaves developed under LL to $\mathrm{HL}$. For $S$. vulgaris, the values for percent increase in transfer-cell plasma membrane length are averages of the mean values obtained from PCs and CCs. For additional information, see Figure 1. 

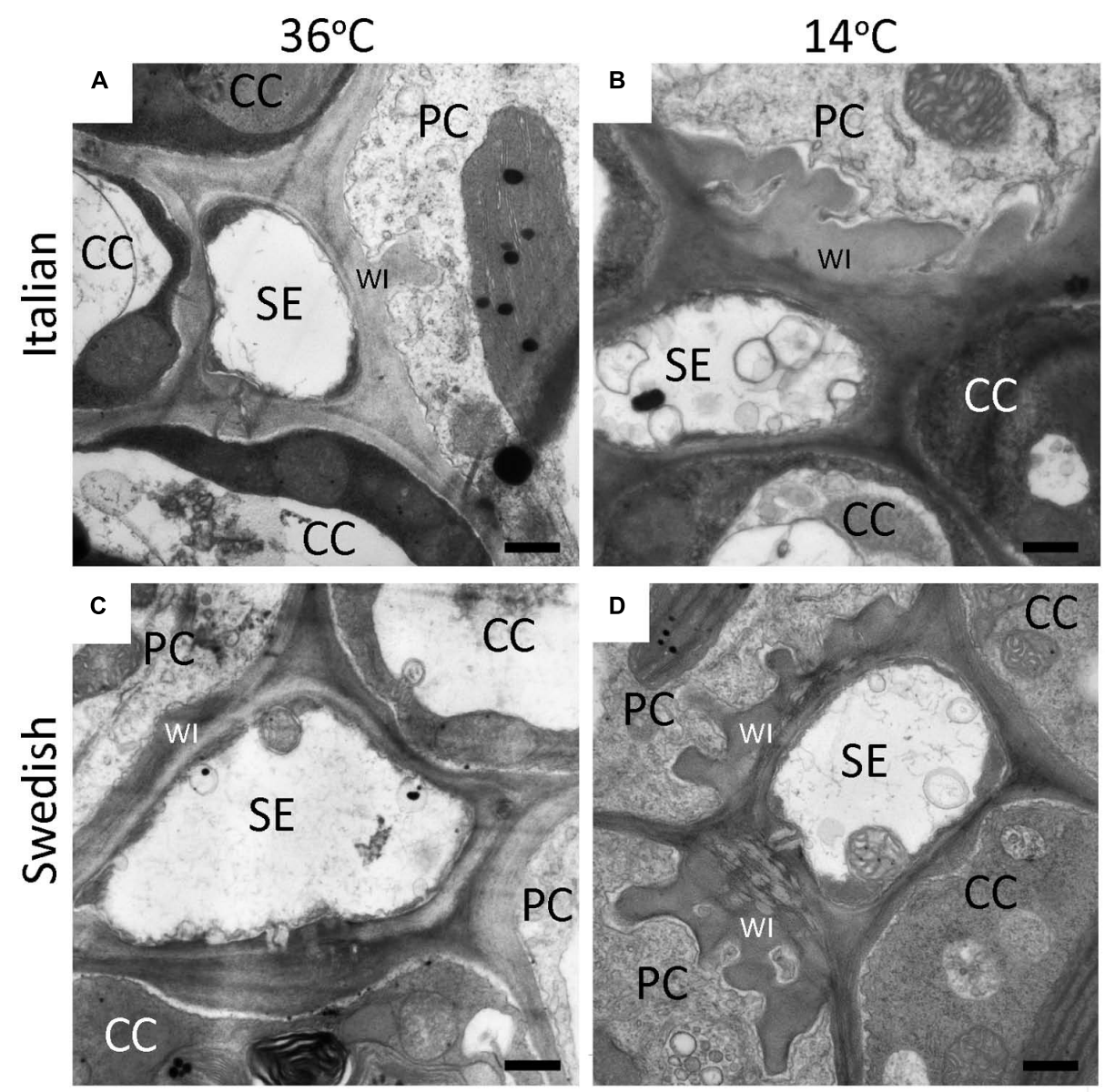

FIGURE 3 | Representative transmission electron-micrographic cross-sectional images of sieve elements (SE) surrounded by parenchyma (PC) and companion (CC) cells in foliar minor veins of Italian $(A, B)$ or Swedish (C,D) ecotypes of $A$. thaliana that developed under $400 \mu \mathrm{mol}$ photons $\mathrm{m}^{-2} \mathrm{~s}^{-1}$ at a daytime leaf temperature of $36^{\circ} \mathrm{C}(\mathrm{A}, \mathrm{C})$ or $14^{\circ} \mathbf{C}(\mathbf{B}, \mathbf{D})$. Cell-wall ingrowths (WI) in the PCs are adjacent to the area abutting a neighboring SE, sometimes extend over the area of adjacent CCs (particularly apparent at lower temperature), and are more pronounced (greater level of invagination) in both ecotypes that developed at lower temperature. Black bar $=500 \mathrm{~nm}$ in length. been demonstrated that reactive-oxygen species play a central role in stimulating such ingrowth formation (Andriunas et al., 2012), as we had postulated previously (Amiard et al., 2007). Any abiotic stress, such as the high growth light or low growth temperatures employed in this study, might be expected to generate higher levels of reactive oxygen species (Suzuki et al., 2012). Wounding through attack by pests or infection by pathogens also leads to elevated levels of reactive oxygen (Bell et al., 1995; Torres, 2010). Increased levels of reactive oxygen can, in turn, be expected to result in increased formation of oxylipin hormones (e.g., jasmonic acid and methyl jasmonate) through peroxidation of polyunsaturated fatty acids (Demmig-Adams et al., 2013). An increase in the synthesis of jasmonate hormones, that stimulate jasmonate responsive genes important to the defense of plants, is one of the major responses of plants to abiotic and biotic (e.g., pathogen and insect attack) stress (Avanci et al., 2010; Ballare, 2011; Kazan and Manners, 2011; Hu et al., 2013; Santino et al., 2013).

The synthesis of jasmonates has, moreover, been localized to the vasculature of plants (Hause et al., 2003; Stenzel et al., 2003;
Howe, 2004). This is perhaps not surprising, given that the PCs are typically the primary cells of the phloem subject to invasion by pathogenic viruses and fungi (Ding et al., 1995, 1998; Heller and Gierth, 2001; Zhou etal., 2002) as a means to gain access to sieve elements for distribution throughout the plant (Gilbertson and Lucas, 1996; Lucas and Wolf, 1999; Waigman et al., 2004; Scholthof, 2005; Vuorinen et al., 2011). The specific localization of PC-cell wall ingrowths to the region adjacent to sieve elements, coupled with the fact that PC wall ingrowth development was stimulated by MeJA, are both consistent with the hypothesis that such augmentation of cell wall material could serve as an increased physical barrier to the transmission of pathogens into the plant vascular system (for further discussion, see Amiard et al., 2007 and Demmig-Adams et al., 2013). Furthermore, the greater level of cell-wall ingrowth in the Italian compared to the Swedish $A$. thaliana ecotype when grown at higher temperature $\left(36^{\circ} \mathrm{C}\right)$ may be related to the higher temperatures naturally experienced by the Italian ecotype (Ågren and Schemske, 2012) as well as the greater susceptibility to pathogenic infection that plants may 


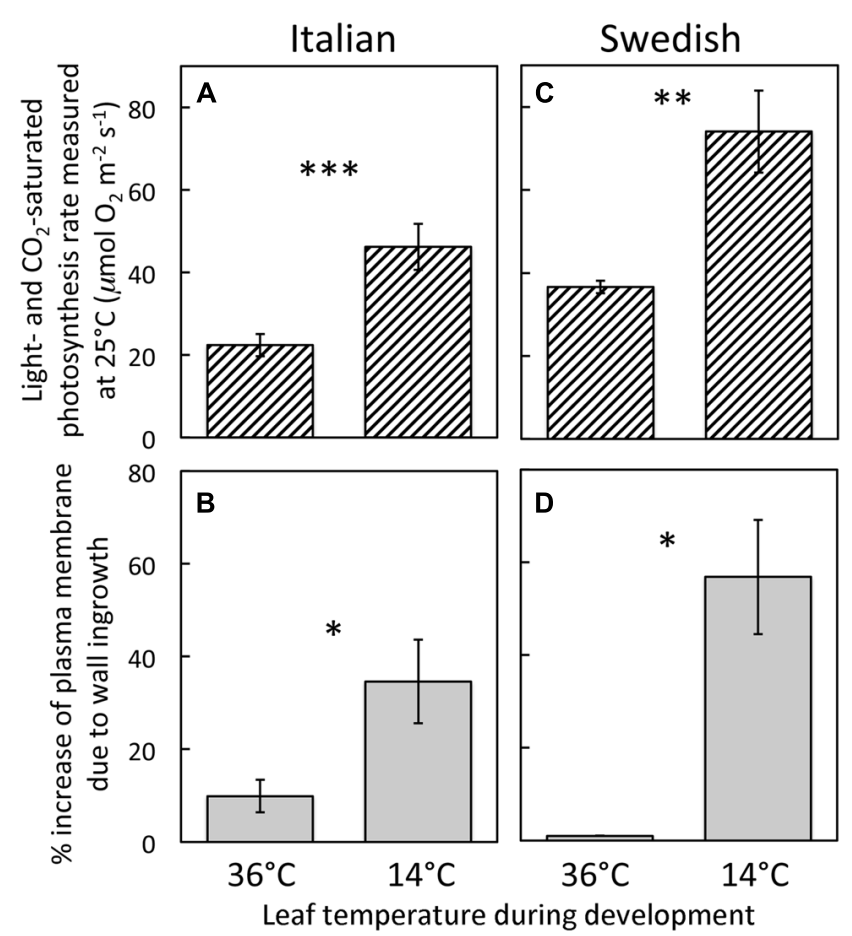

FIGURE 4 | (A,C) Foliar light- and $\mathrm{CO}_{2}$-saturated rate of photosynthetic oxygen evolution ascertained at $25^{\circ} \mathrm{C}$ and $\mathbf{( B , D )}$ percent increase in plasma-membrane length due to cell-wall ingrowths estimated from cross-sections of phloem-parenchyma transfer cells relative to the hypothetical membrane area in the absence of wall ingrowths in foliar minor veins of Italian $(\mathbf{A}, \mathbf{B})$ and Swedish $(\mathbf{C}, \mathbf{D})$ ecotypes of
A. thaliana that developed under $400 \mu \mathrm{mol}$ photons $\mathrm{m}^{-2} \mathrm{~s}^{-1}$ at daytime leaf temperatures of 36 or $14^{\circ} \mathrm{C}$. Significant differences between the means within each ecotype are denoted by asterisks $\left({ }^{*} P<0.05,{ }^{*} P<0.01\right.$, and $\left.{ }^{* *} P<0.001\right)$. Photosynthetic capacities from leaves that developed at $14^{\circ} \mathrm{C}$ from Cohu etal. (2013b). experience at elevated temperature (Celebi-Toprak et al., 2003; Qu et al., 2005).

While higher light and lower temperature both represent conditions of potentially greater levels of excess light and therefore the potential for higher levels of reactive oxygen formation, they also represent the opportunity for higher rates of photosynthesis. The greater energy content of a higher flux of photons can be beneficial for any species capable of upregulating photosynthesis in the absence of environmental and/or genetic constraints (Amiard et al., 2005), and winter annual species likewise respond to lower temperature with strong upregulation of photosynthesis (Cohu et al., 2013b, 2014). The significant correlation between the level of minor-vein phloem cell wall ingrowths and photosynthetic capacity in the leaves of multiple species/ecotypes grown under different conditions of light and temperature documented here would be consistent with a role of these transfer cells in supporting foliar export of the products of photosynthesis. The increase in plasma membrane resulting from such ingrowths may thus serve to facilitate greater levels of assimilate export through (1) an increased area for sugar efflux from PCs into the apoplast adjacent to the sieve elements and CCs or from the apoplast to the cytosol of the CC transfer cells, (2) increased levels of ATPases for actively transporting protons from the cytosol of the transfer cells to the apoplast, and (3) increased levels of $\mathrm{H}^{+}$-sucrose symporters for moving sucrose from the apoplast into CC transfer cells as a critical step in the active loading of the phloem (Pate and Gunning, 1972; Gunning and Pate, 1974; Kühn, 2003; Offler et al., 2003; Sondergaard et al., 2004; Amiard et al., 2007). Cell-wall ingrowths provide a scaffold on which to lay down a significantly higher plasmamembrane area in which greater numbers of membrane-spanning transport proteins can be embedded. It should be kept in mind, however, that the metric assessed in the present study, as a twodimensional measure of cell membrane length from cross-sections of transfer cells, can only serve as a proxy for the actual magnified membrane area arising from the labyrinth of cell-wall ingrowths.

It has been firmly established that the level of demand for products of photosynthesis by distant sinks in the plant can influence the rate of photosynthesis in source leaves, e.g., higher levels of utilization of sugars through metabolism, growth, and/or storage by heterotrophic, non-photosynthetic tissues result in higher rates of photosynthesis (Paul and Foyer, 2001; Körner, 2013). However, recent evidence indicates that features influencing the flux of reduced carbohydrates between photosynthetic mesophyll cells of the leaf and the plant's sinks may also play a role in setting the upper ceiling for photosynthesis (Amiard et al., 2005; Adams et al., 2007, 2013; Cohu et al., 2013b, 2014; Muller et al., 2014; see also Ainsworth and Bush, 2011). Thus, despite the association between the degree of foliar minor-vein phloem cell-wall ingrowth and photosynthesis demonstrated in the present study, this relationship is only correlative in nature and should be considered as one 


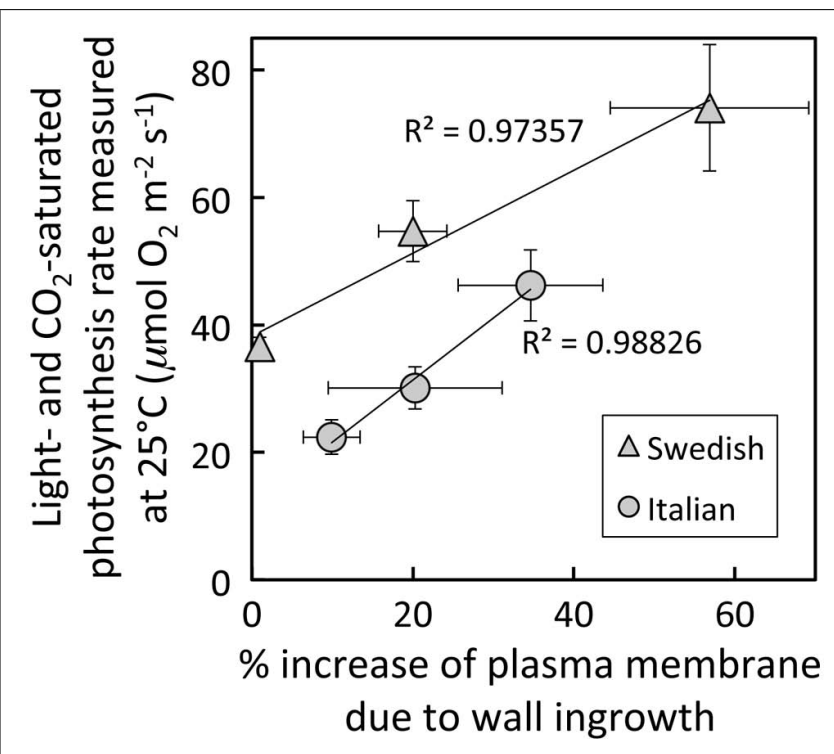

FIGURE 5 | Relationship between the percent increase of parenchyma-cell plasma-membrane length in foliar minor veins and photosynthetic capacity from leaves of Italian (circles) or Swedish (triangles) ecotypes of $A$. thaliana that developed under $400 \mu \mathrm{mol}$ photons $\mathrm{m}^{-2} \mathrm{~s}^{-1}$ at a daytime leaf temperature of $36^{\circ} \mathrm{C}$ (lowest values), $18^{\circ} \mathrm{C}$ (intermediate values), or $14^{\circ} \mathrm{C}$ (highest values). The linear relationship among all six values (not shown) was significant at $P<0.05$, whereas the linear relationships shown for each ecotype were not. Photosynthetic capacities from leaves that developed at $14^{\circ} \mathrm{C}$ from Cohu etal. (2013b). of a suite of features that may be co-regulated and contribute to facilitating a given maximal rate of photosynthesis. For instance, in the case of $A$. thaliana (three ecotypes grown under four different sets of environmental conditions), we recently showed (Cohu et al., 2013b) that photosynthetic capacity is significantly correlated with number and cross-sectional area of minor-vein phloem cells (sieve elements, as well as CCs + PCs). In fact, the higher rate of photosynthesis for a given level of foliar minor-vein PC wall ingrowth in the Swedish compared to the Italian ecotype of A. thaliana shown in the present study may be related to higher numbers and a greater cross-sectional area of minor vein phloem cells in leaves of the Swedish ecotype relative to the Italian ecotype (Cohu et al., 2013a,b). Furthermore, across multiple species that load foliar veins apoplastically, photosynthetic capacity was significantly correlated with the product of foliar vein density and the number of phloem cells (Adams et al., 2013; Cohu et al., 2014; Muller et al., 2014). In addition, symplastic loaders do not have minor-vein phloem transfer cells, nor are transfer cells even present in all apoplastic loaders. Thus the degree to which minor-vein transfer cell walls are invaginated is an attractive candidate for being a contributor to the maximal photosynthesis that a leaf can exhibit, but is only one factor among many including, e.g., the number of palisade cell layers, vein density, characteristics of the xylem supplying water to the leaves, and other features of the phloem (Amiard et al., 2005; Dumlao et al., 2012; Cohu et al., 2013b, Cohu et al., 2014; Muller et al., 2014). The correlations between photosynthesis rate and phloem-cell wall invagination presented here clearly warrant further inquiry into a role of both CC and PC wall

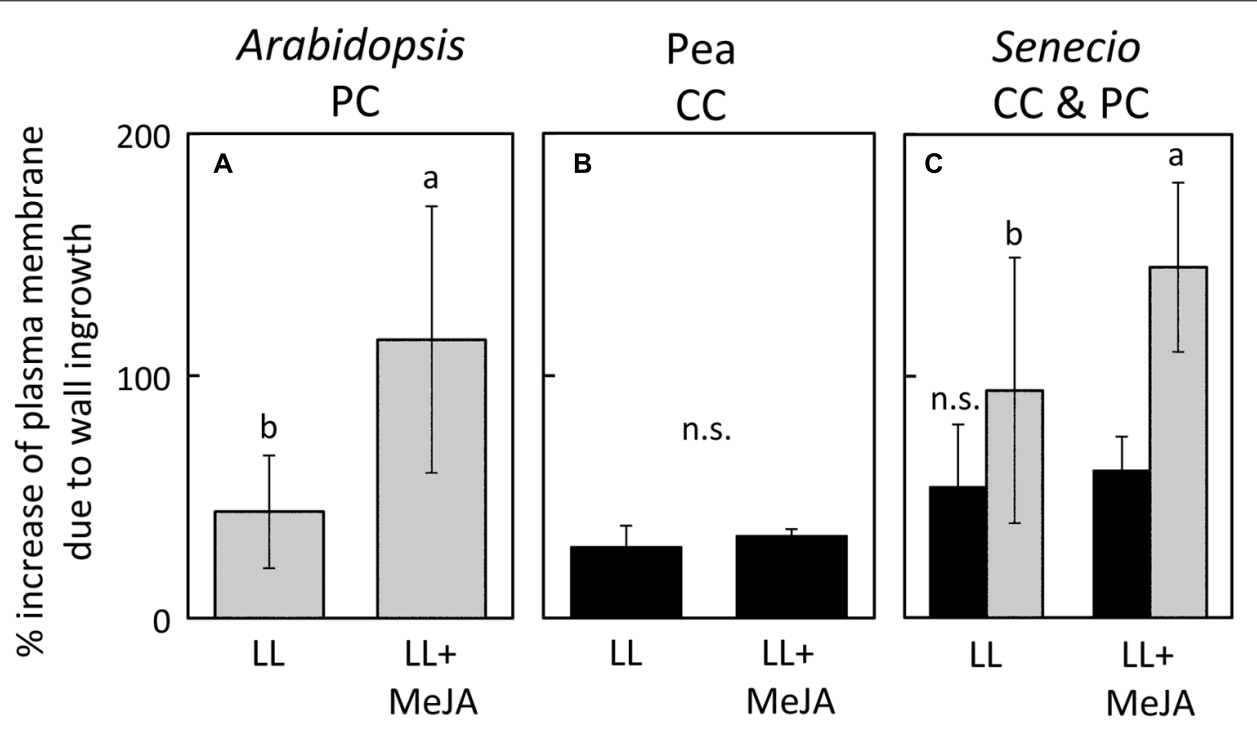

Growth at low light with or without MeJA treatment

FIGURE 6 | Percent increase in plasma-membrane length due to cell-wall ingrowths estimated from cross-sections of phloem transfer cells (parenchyma $=\mathrm{PC}$, companion $=\mathrm{CC}$ ) relative to the hypothetical membrane area in the absence of wall ingrowths in foliar minor veins of $A$. thaliana (A), pea (B), and $S$. vulgaris (C) that developed in low light and were sprayed with a $0.05 \%$ solution of Tween (LL) or a $0.05 \%$ solution of Tween with $10 \mu \mathrm{M}$ methyl jasmonate ( $L L+M e J A)$ for seven days. Gray columns indicate PCs and black columns indicate CCs. Significant differences between the means $(P<0.05)$ of $A$. thaliana $(\mathbf{A})$ and $S$. vulgaris $(\mathbf{C})$ are denoted by different lower case letters. Percent increase of plasma membrane length was not significantly different (n.s.) between control and MeJA-treated companion cells of either pea (B) or S. vulgaris (C). Data from Amiard etal. (2007). 
invagination in sugar export. Especially for the case of PC wall invaginations, the contrasting possible roles in sugar export versus obstruction of pathogen spread should be elucidated.

\section{ACKNOWLEDGMENTS}

Supported by the National Science Foundation (Award Numbers IBN-0235351 and DEB-1022236 to Barbara Demmig-Adams and William W. Adams) and the University of Colorado at Boulder. We thank our colleagues Profs. Douglas Schemske and Jon Agren for providing seeds of the Arabidopsis ecotypes, Tyler Dowd for embedding and cutting of some tissue samples, and Dr. Onno Muller for some photosynthesis measurements.

\section{REFERENCES}

Adams, W. W. III., Cohu, C. M., Muller, O., and Demmig-Adams, B. (2013). Foliar phloem infrastructure in support of photosynthesis. Front. Plant Sci. 4:194. doi: 10.3389/fpls.2013.00194

Adams, W. W. III., Watson, A. M., Mueh, K. E., Amiard, V., Turgeon, R., Ebbert, V., et al. (2007). Photosynthetic acclimation in the context of structural constraints to carbon export from leaves. Photosynth. Res. 94, 455-466. doi: 10.1007/s11120006-9123-3

Ågren, J., and Schemske, D. W. (2012). Reciprocal transplants demonstrate strong adaptive differentiation of the model organism Arabidopsis thaliana in its native range. New Phytol. 194, 1112-1122. doi: 10.1111/j.1469-8137. 2012.04112.x

Ainsworth, E. A., and Bush, D. R. (2011). Carbohydrate export from the leaf: a highly regulated process and target to enhance photosynthesis and productivity. Plant Physiol. 155, 64-69. doi: 10.1104/pp.110.167684

Amiard, V., Demmig-Adams, B., Mueh, K. E., Turgeon, R., Combs, A. F., and Adams, W. W. III. (2007). Role of light and jasmonic acid signaling in regulating foliar phloem cell wall ingrowth development. New Phytol. 173, 722-731. doi: 10.1111/j.1469-8137.2006.01954.x

Amiard, V., Mueh, K. E., Demmig-Adams, B., Ebbert, V., Turgeon, R., and Adams, W. W. III. (2005). Anatomical and photosynthetic acclimation to the light environment in species with differing mechanisms of phloem loading. Proc. Natl. Acad. Sci. U.S.A. 102, 12968-12973. doi: 10.1073/pnas.0503784102

Andriunas, F. A., Zhang, H. M., Xia, X., Offler, C. E., McCurdy, D. W., and Patrick, J. W. (2012). Reactive oxygen species form part of a regulatory pathway initiating trans-differentiation of epidermal transfer cells in Vicia faba cotyledons. J. Exp. Bot. 63, 3617-3629. doi: 10.1093/jxb/ers029

Arun Chinnappa, K. S., Nguyen, T. T. S., Hou, J., Wu, Y., and McCurdy, D. W. (2013). Phloem parenchyma transfer cells in Arabidopsis - an experimental system to identify transcriptional regulators of wall ingrowth formation. Front. Plant Sci. 4:102. doi: 10.3389/fpls.2013.00102

Avanci, N. C., Luche, D. D., Goldman, G. H., and Goldman, M. H. S. (2010). Jasmonates are phytohormones with multiple functions, including plant defense and reproduction. Gen. Mol. Res. 9, 484-505. doi: 10.4238/vol9-1gmr754

Ballare, C. L. (2011). Jasmonate-induced defenses: a tale of intelligence, collaborators and rascals. Trends Plant Sci. 16, 249-257. doi: 10.1016/j.tplants.2010. 12.001

Bell, E., Creelman, R. A., and Mullet, J. E. (1995). A chloroplast lipoxygenase is required for wound-induced jasmonic acid accumulation in Arabidopsis. Proc. Natl. Acad. Sci. U.S.A. 92, 8675-8679.

Borisjuk, L., Wang, T. L., Rolletschek, H., Wobus, U., and Weber, H. (2002). A pea seed mutant affected in the differentiation of the embryonic epidermis is impaired in embryo growth and seed maturation. Development 129, 1595-1607.

Celebi-Toprak, F., Slack, S. A., and Russo, P. (2003). Potato resistance to cucumber mosaic virus is temperature sensitive and virus-strain specific. Breed. Sci. 53, 69-75. doi: 10.1270/jsbbs.53.69

Cohu, C. M., Muller, O., Demmig-Adams, B., and Adams, W. W. III. (2013a). Minor loading vein acclimation for three Arabidopsis thaliana ecotypes in response to growth under different temperature and light regimes. Front. Plant Sci. 4:240. doi: $10.3389 /$ fpls.2013.00240

Cohu, C. M., Muller, O., Stewart, J. J., Demmig-Adams, B., and Adams, W. W. III. (2013b). Association between minor loading vein architecture and light- and $\mathrm{CO}_{2}$-saturated photosynthetic oxygen evolution among Arabidopsis thaliana ecotypes from different latitudes. Front. Plant Sci. 4:264. doi: 10.3389/fpls.2013.00264

Cohu, C. M., Muller, O., Adams, W. W. III., and Demmig-Adams, B. (2014). Leaf anatomical and photosynthetic acclimation to cool temperature and high light in two winter versus two summer annuals. Physiol. Plant. doi: 10.1111/ppl.12154 [Epub ahead of print].

Delieu, T., and Walker, D. A. (1981). Polarographic measurement of photosynthetic oxygen evolution by leaf discs. New Phytol. 89, 165-178. doi: 10.1111/j.14698137.1981.tb07480.x

Demmig-Adams, B., Cohu, C. M., Amiard, V., Zadelhoff, G., Veldink, G. A., Muller, O., et al. (2013). Emerging trade-offs - impact of photoprotectants (PsbS, xanthophylls, and vitamin E) on oxylipins as regulators of development and defense. New Phytol. 197, 720-729. doi: 10.1111/nph.12100

Ding, X. S., Carter, S. A., Deom, C. M., and Nelson, R. S. (1998). Tobamovirus and potyvirus accumulation in minor veins of inoculated leaves from representatives of the Solanaceae and Fabaceae. Plant Physiol. 116, 125-136. doi: 10.1104/pp.116.1.125

Ding, X. S., Shintaku, M. H., Arnold, S. A., and Nelson, R. S. (1995). Accumulation of mild and severe strains of tobacco mosaic virus in minor veins of tobacco. Mol. Plant Microbe Interact. 8, 32-40. doi: 10.1094/MPMI-8-0032

Dumlao, M. R., Darehshouri, A., Cohu, C. M., Muller, O., Mathias, J., Adams, W. W. III., et al. (2012). Low temperature acclimation of photosynthetic capacity and leaf morphology in the context of phloem loading type. Photosynth. Res. 113, 181-189. doi: 10.1007/s11120-012-9762-5

Edwards, J., Martin, A. P., Andriunas, F., Offler, C. E., Patrick, J. W., and McCurdy, D. W. (2010). GIGANTEA is a component of a regulatory pathway determining wall ingrowth deposition in phloem parenchyma transfer cells of Arabidopsis thaliana. Plant J. 63, 651-661. doi: 10.1111/j.1365-313X.2010.04269.x

Gilbertson, R. I., and Lucas, W. J. (1996). How do viruses traffic on the 'vascular highway'? Trends Plant Sci. 1, 260-268. doi: 10.1016/1360-1385(96)10029-7

Gunning, B. E. S., and Pate, J. S. (1974). “Transfer cells," in Dynamic Aspects of Plant Ultrastructure, ed. A. W. Robards (London: McGraw-Hill), 441-479.

Gunning, B. E. S., Pate, J. S., and Briarty, L. G. (1968). Specialized "transfer cells" in minor veins of leaves and their possible significance in phloem translocation. J. Cell Biol. 37, 7-12. doi: 10.1083/jcb.37.3.C7

Haritatos, E., Medville, R., and Turgeon, R. (2000). Minor vein structure and sugar transport in Arabidopsis thaliana. Planta 211, 105-111. doi: $10.1007 / \mathrm{s} 004250000268$

Hause, B., Hause, G., Kutter, C., Miersch, O., and Wasternack, C. (2003). Enzymes of jasmonate biosynthesis occur in tomato sieve elements. Plant Cell Physiol. 44, 643-648. doi: 10.1093/pcp/pcg072

Heller, A., and Gierth, K. (2001). Cytological observations of the infection process by Phomopsis helianthi (Munt.-Cvet) in leaves of sunflower. J. Phytopathol. 149, 347-357. doi: 10.1046/j.1439-0434.2001.00635.x

Henry, Y., and Steer, M. W. (1980). A re-examination of the induction of phloem transfer cell development in pea leaves (Pisum sativum). Plant Cell Environ. 3, 377-380. doi: 10.1111/1365-3040.ep11581888

Howe, G. A. (2004). Jasmonates as signals in the wound response. J. Plant Growth Reg. 23, 223-237. doi: 10.1007/s00344-004-0030-6

Hu, P., Zhou, W., Cheng, Z. W., Fan, M., Wang, L., and Xie, D. X. (2013). JAV1 controls jasmonate-regulated plant defense. Mol. Cell 50, 504-515. doi: 10.1016/j.molcel.2013.04.027

Kazan, K., and Manners, J. M. (2011). The interplay between light and jasmonate signalling during defence and development. J. Exp. Bot. 62, 4087-4100. doi: 10.1093/jxb/err142

Körner, C. (2013). Growth controls photosynthesis - mostly. Nova Acta Leopoldina NF 114, 273-283.

Kühn, C. (2003). A comparison of the sucrose transporter systems of different plant species. Plant Biol. 5, 215-232. doi: 10.1055/s-2003-40798

Lucas, W. J., and Wolf, S. (1999). Connections between virus movement, macromolecular signaling and assimilate allocation. Curr. Opin. Plant Biol. 2, 192-197. doi: 10.1016/S1369-5266(99)80035-1

Muller, O., Cohu, C. M., Stewart, J. J., Protheroe, J. A., Demmig-Adams, B., and Adams, W. W. III. (2014). Association between photosynthesis and contrasting features of minor veins in leaves of summer annuals loading phloem via symplastic versus apoplastic routes. Physiol. Plant. doi: 10.1111/ppl.12155 [Epub ahead of print]. 
Offler, C. E., McCurdy, D. W., Patrick, J. W., and Talbot, M. J. (2003). Transfer cells: cells specialized for a special purpose. Annu. Rev. Plant Biol. 54, 431-454. doi: 10.1146/annurev.arplant.54.031902.134812

Pate, J. S., and Gunning, B. E. S. (1969). Vascular transfer cells in angiosperm leaves. A taxonomic and morphological survey. Protoplasma 68, 135-156. doi: 10.1007/BF01247901

Pate, J. S., and Gunning, B. E. S. (1972). Transfer cells. Annu. Rev. Plant Physiol. 23, 173-196. doi: 10.1146/annurev.pp.23.060172.001133

Paul, M. J., and Foyer, C. H. (2001). Sink regulation of photosynthesis. J. Exp. Bot. 52, 1383-1400. doi: 10.1093/jexbot/52.360.1383

Pugh, D. A., Offler, C. E., Talbot, M. J., and Ruan, Y. L. (2010). Evidence for the role of transfer cells in the evolutionary increase in seed and fiber biomass yield in cotton. Mol. Plant 3, 1075-1086. doi: 10.1093/mp/ssq054

Qu, F., Ye, X. H., Hou, G. C., Sato, S., Clemente, T. E., and Morris, T. J. (2005). RDR6 has a broad but temperature-dependent antiviral defense role in Nicotiana benthamiana. J. Virol. 79, 15209-15217. doi: 10.1128/JVI.79.24.15209-15217.2005

Santino, A., Taurino, M., DeDominico, S., Bonsegna, S., Poltronieri, P., Pastor, V., et al. (2013). Jasmonate signaling in plant development and defense response to multiple (a)biotic stresses. Plant Cell Rep. 32, 1085-1098. doi: 10.1007/s00299013-1441-2

Scholthof, H. B. (2005). Plant virus transport: motions of functional equivalence. Trends Plant Sci. 10, 376-382. doi: 10.1016/j.tplants.2005.07.002

Sondergaard, T. E., Schulz, A., and Palmgren, M. G. (2004). Energization of transport processes in plants. Roles of the plasma membrane $\mathrm{H}^{+}$-ATPase. Plant Physiol. 136, 2475-2482. doi: 10.1104/pp.104.048231

Stenzel, I., Hause, B., Maucher, H., Pitzschke, A., Miersch, O., Ziegler, J., et al. (2003). Allene oxide cyclase dependence of the wound response and vascular bundle-specific generation of jasmonates in tomato - amplification in wound signalling. Plant J. 33, 577-589. doi: 10.1046/j.1365-313X.2003.01647.x

Suzuki, N., Koussevitsky, S., Mittler, R., and Miller, G. (2012). ROS and redox signaling in the response of plants to abiotic stress. Plant Cell Environ. 35, 259-270. doi: $10.1111 / j .1365-3040.2011 .02336 . x$
Torres, M. A. (2010). ROS in biotic interactions. Physiol. Plant. 138, 414-429. doi: 10.1111/j.1399-3054.2009.01326.x

Vuorinen, A. L., Kelloniemi, J., and Valkonen, J. P. T. (2011). Why do viruses need phloem for systemic invasion of plants? Plant Sci. 181, 355-363. doi: 10.1016/j.plantsci.2011.06.008

Waigman, E., Ueki, S., Trutnyeva, K., and Citovsky, V. (2004). The ins and outs of nondestructive cell-to-cell systemic movement of plant viruses. Crit. Rev. Plant Sci. 23, 195-250. doi: 10.1080/07352680490452807

Wimmers, J. W., and Turgeon, R. (1991). Transfer cells and solute uptake in minor veins of Pisum sativum leaves. Planta 186, 2-12. doi: 10.1007/BF00201491

Zhou, C. L. E., El-Desouky, A., Sheta, H., Kelley, S., Polek, M., and Ullman, D. E. (2002). Citrus tristeza virus ultrastructure and associated cytopathology in Citrus sinensis and Citrus aurantifolia. Can. J. Bot. 80, 512-525. doi: 10.1139/ b02-030

Conflict of Interest Statement: The authors declare that the research was conducted in the absence of any commercial or financial relationships that could be construed as a potential conflict of interest.

Received: 27 November 2013; accepted: 21 January 2014; published online: 06 February 2014.

Citation: Adams WW III, Cohu CM, Amiard V and Demmig-Adams B (2014) Associations between the acclimation of phloem-cell wall ingrowths in minor veins and maximal photosynthesis rate. Front. Plant Sci. 5:24. doi: 10.3389/fpls.2014.00024

This article was submitted to Plant Physiology, a section of the journal Frontiers in Plant Science.

Copyright (C) 2014 Adams III, Cohu, Amiard and Demmig-Adams. This is an openaccess article distributed under the terms of the Creative Commons Attribution License (CC BY). The use, distribution or reproduction in other forums is permitted, provided the original author(s) or licensor are credited and that the original publication in this journal is cited, in accordance with accepted academic practice. No use, distribution or reproduction is permitted which does not comply with these terms. 